\title{
Analisis Sensitivitas terhadap Metode WP dan VIKOR dalam Pengambilan Keputusan Penentuan Penerima Beasiswa di UNJ
}

\author{
Ghefira Nur Kahfi1 ${ }^{1, a)}$, Sudarwanto ${ }^{1, \text { b) }}$, Siti Rohmah Rohimah ${ }^{1, c)}$ \\ ${ }^{1}$ Program Studi Matematika, Fakultas Ilmu Pengetahuan Alam, Universitas Negeri Jakarta \\ Email : ${ }^{a)}$ gnurkahfi@yahoo.co.id, b) sudarwanto@unj.ac.id, c) sitirohmah@unj.ac.id
}

\begin{abstract}
Kartu Jakarta Mahasiswa Unggul (KJMU) is one of the scholarship programs available at UNJ and is funded by the DKI Jakarta Regional Budget. The recipients increase every year but the costs incurred remain so that a proper Sistem Penerimaan Keputusan (SPK) is needed. One of the SPK methods is the Weighted Product Model (WPM) and Vi̊je Kriterijumska Optimazajica I Kompromiso Resenje method (VIKOR). The WP method begins by calculating the weight of each criterion and then ranking it. Meanwhile, the VIKOR ranking method is seen based on compromise solutions. Next, a sensitivity test was conducted to see how sensitive the two methods were to changes that occurred. This research was conducted 3 times and obtained an average percentage change in ranking results of 16,776\% for the WP method and $18,156 \%$ for the VIKOR method, so that the VIKOR method is more appropriate to be applied in the KJMU scholarship acceptance decision system at UNJ.
\end{abstract}

Keywords: scholarship, weighted, ranking

\begin{abstract}
Abstrak
Kartu Jakarta Mahasiswa Unggul (KJMU) adalah salah satu program beasiswa yang terdapat di UNJ dan dibiayai oleh anggaran APBD DKI Jakarta. Penerimanya setiap tahun meningkat tetapi biaya yang dikeluarkan tetap sehingga diperlukan adanya sistem pendukung keputusan (SPK) yang tepat. Di antara metode SPK yang dikenal adalah Weighted Product Model (WPM) dan ViÅje Kriterijumska Optimazajica I Kompromiso Resenje (VIKOR). Metode WP dimulai dengan menghitung bobot masingmasing kriteria kemudian dilakukan perankingan. Sedangkan pemeringkatan metode VIKOR dilihat berdasarkan solusi kompromi. Selanjutnya dilakukan uji sensitivitas untuk melihat seberapa sensitif kedua metode tersebut terhadap perubahan yang terjadi. Penelitian ini dilakukan sebanyak 3 kali percobaan dan diperoleh hasil rata-rata persentase perubahan ranking sebesar $16.776 \%$ untuk metode WP dan $18.156 \%$ untuk metode VIKOR, sehingga metode VIKOR lebih tepat diterapkan dalam sistem keputusan penerimaan beasiswa KJMU di UNJ
\end{abstract}

Kata Kunci : beasiswa, bobot, ranking

\section{PENDAHULUAN}

Pendidikan merupakan salah satu jembatan menuju kesuksesan. Semua orang berhak menerima pendidikan, tetapi tidak semua orang dapat menempuh pendidikan. Oleh karena itu, diciptakan program beasiswa yang digunakan untuk meringankan biaya Pendidikan.

UNJ merupakan salah satu lembaga pendidikan yang menyediakan beberapa program beasiswa

Diterima: 6 Agustus 2021, Direvisi: 27 Februari 2022, Disetujui: 27 Januari 2022 
diantaranya KJMU, bidikmisi, Djarum, dan KIP. Penulisan ini akan mengkaji program beasiswa KJMU. Alasannya, penerima KJMU terus meningkat setiap tahunnya sedangkan anggarannya tetap dan pihak KJMU belum memiliki sistem pendukung keputusan yang tepat (Elfianty dan Wahyudi, 2020) htt

Sistem Pendukung Keputusan (SPK) merupakan alat pendukung keputusan dalam matematika. SPK menurut Lombing adalah sistem yang interaktif untuk membantu mengambil keputsan berdasarkan data dan model yang dibagi menjadi 2 kategori, yakni pengambilan keputusan dengan 1 kriteria dan multikriteria. Dalam kesempatan kali ini, akan dibahas SPK multikriteria dengan metode Weighted Product Model yang dilanjutkan dengan Metode VIKOR.

Penelitian ini bertujuan untuk mendistribusikan biaya beasiswa KJMU agar lebih maksimal dengan adanya regenerasi penerima di setiap pendaftaran sehingga diperlukan suatu metode dengan tingkat sensitivitas lebih tinggi.

\section{LANDASAN TEORI}

\section{Beasiswa}

Beasiswa merupakan bantuan berupa biaya pendidikan yang diberikan oleh suatu instansi untuk menunjang kegiatan pendidikan dan meningkatkan kualitas pendidikan (Rainer, 2017). Sedangkan kata beasiswa menurut KBBI (https://kbbi.web.id/beasiswa) adalah tunjangan yang diberikan kepada pelajar guna untuk memenuhi biaya pendidikan. Beasiswa juga merupakan bentuk penghargaan atas prestasi yang dicapai selama proses belajar. Pemberian beasiswa dapat berupa dana dan fasilitas seperti buku, alat, maupun tempat tinggal yang digunakan untuk menunjang kegiatan pendidikan. Adapun tujuan dari beasiswa yakni, meningkatkan kualitas pendidikan, meningkatkan prestasi akademik dan meningkatkan semangat pelajar untuk memperoleh pendidikan yang lebih baik.

\section{Multiple Atribute Decision Making (MADM)}

MADM adalah salah satu metode untuk menentukan keputusan dengan banyak kriteria (Rao, 2013). Metode MADM memiliki tiga tahap penyelesaian sebagai berikut :

1. Penyusunan Kriteria

Melakukan identifikasi kriteria berupa penyusunan masalah, alternatif keputusan, serta menentukan spesifikasi dan tujuan.

2. Analisis

Tahap ini didahului dengan membuat kondisi-kondisi tertentu yang akan terjadi dan dilanjutkan dengan memilih keutamaan dari setiap nilai dan mengacuhkan yang lain.

3. Sintesis Informasi

Pada tahap ini dilakukan penerapan metode MADM.(Rao, 2007).

Dalam metode MADM perlu dibentuk suatu matriks yang disebut matriks kriteria-alternatif. Matriks kriteria-altenatif dibentuk berdasarkan alternatif keputusan dan kriteria tujuan. Matriks ini digunakan untuk mempermudah penerapan metode yang terdapat dalam MADM.

Misal $A=\left\{a_{s} \mid s=1,2, \cdots, k\right\}$ adalah himpunan alternatif keputusan dan $K=\left\{k_{t} \mid t=1,2, \cdots, l\right\}$ adalah himpunan kriteria. Selanjutnya akan ditentukan alternatif $x^{\prime}$ yang memiliki harapan tinggi dan berkaitan dengan kriteria $k_{l}$. Kemudian alternatif dan tujuan dibentuk ke dalam matriks $\mathrm{P}$ yang berukuran $k \times l$ sebagai berikut :

$$
\begin{aligned}
& \begin{array}{llll}
K_{1} & K_{2} & K_{3} & K_{4}
\end{array} \\
& P=\begin{array}{c}
A_{1} \\
A_{2} \\
\vdots \\
A_{k}
\end{array}\left(\begin{array}{cccc}
p_{11} & p_{12} & \cdots & p_{1 l} \\
p_{21} & p_{22} & \cdots & p_{2 l} \\
\vdots & \vdots & \ddots & \vdots \\
p_{k 1} & p_{k 2} & \cdots & p_{k l}
\end{array}\right)
\end{aligned}
$$


dimana $p_{11}$ adalah bobot alternatif ke-1 dengan kriteria ke-1. Selanjutnya $p_{12}$ adalah bobot alternatif ke-1 dengan kriteria ke-2, demikian selanjutnya hingga $p_{k l}$ adalah bobot alternatif ke-s terhadap kriteria ke- $t$.

\section{Weighted Product Method (WPM)}

Weighted Product Method atau WPM merupakan salah satu dari metode MADM. Metode WPM menggunakan perkalian untuk menghubungkan ranking atribut yang masing-masing dipangkatkan dengan bobot atribut (Yeh, 2002). Proses ini disebut juga dengan normalisasi. Berikut adalah tahapan dalam metode WPM : [1.]

1. Tentukan kriteria dan alternatif keputusan.

2. Tentukan bobot awal $(w)$ masing-masing kriteria yang menunjukkan tingkat kepentingan $\operatorname{dimana} \sum_{n=1}^{k} w_{n}=1$

3. Menyusun matriks kriteria dari alternatif seperti pada persamaan (1).

4. Menghitung nilai $S_{s}$.

$$
S_{s}=\prod_{n=1}^{l}\left(x_{s n}\right)^{(-1)^{n_{n}} w_{n}} ; \quad s=1,2, \cdots, k \text {. }
$$

5. Menghitung nilai $v_{s}$.

$$
v_{s}=\frac{s_{s}}{\sum_{n=1}^{k} s_{n}} ; \quad s=1,2, \cdots, k
$$

6. Perankingan.

\section{Metode VIKOR}

Metode VIKOR merupakan modifikasi dari metode AHP yang terdapat dalam MADM. Metode ini berfokus pada peringkatan dan pemilihan dari beberapa alternatif dan menentukan solusi kompromi. Metode VIKOR diawali dengan menyusun matiks kriteria-alternatif dan dilanjutkan dengan normalisasi dan menghitung nilai preferensi. Metode VIKOR dapat dijalankan berdasarkan algoritma berikut :

1. Tentukan kriteria dan alternatif keputusan.

2. Tentukan bobot awal $(w)$ masing-masing kriteria yang menunjukkan tingkat kepentingan dimana $\sum_{n=1}^{k} w_{n}=1$

3. Menyusun matriks kriteria dari alternatif seperti pada persamaan (1).

4. Melakukan normalisasi matriks $\left(R_{s t}\right)$ untuk mendapat solusi optimal setiap kriteria.

$$
R_{s t}=\frac{\left(P_{t}^{*}-P_{s t}\right)}{\left(P_{t}^{*}-p_{t}{ }^{-}\right)}
$$

5. Menghitung normalisasi bobot $\left(P_{s t}^{*}\right)$

$$
P_{s t}^{*}=w_{t} \times R_{s t}
$$

6. Menghitung nilai utility measure $\left(S_{s}\right)$ dan regret measure $\left(R_{s}\right)$ dari setiap alternatif

dan

$$
S_{s}=\sum_{n=1}^{k} w_{n} \frac{\left(P_{t}^{*}-P_{s t}\right)}{\left(P_{t}^{*}-P_{t}^{2}\right)}
$$

$$
R_{s}=\max _{n}\left[w_{n} \frac{\left(P_{t}^{*}-P_{s t}\right)}{\left(P_{t}^{*}-P_{t}\right)}\right]
$$

7. Menghitung nilai indeks VIKOR $Q_{s}, s=1,2, \cdots, m$

$$
Q_{s}=v \frac{\left(s_{s}-s^{*}\right)}{\left(s^{-}-s^{*}\right)}+(1-v) \frac{\left(R_{s}-R^{*}\right)}{\left(R^{-}-R^{*}\right)}
$$


8. Melakukan perankingan alternatif dari Nilai VIKOR $\left(S_{s}, R_{s}\right.$ dan $\left.Q_{s}\right)$ dengan kondisi : [-]

(a) AccepTabel advantage

$$
|Q(i)-Q(j)| \geq D Q
$$

dimana, $Q_{i}$ adalah alternatif urutan ke- $i$ dan $Q_{i}$ adalah alternatif urutan ke- $(i+1)$ dalam perankingan $\mathrm{Q}$ dan $D Q=\frac{1}{k-1} ; k$ adalah banyaknya alternatif.

(b) AccepTabel Stability in decision making

keputusan berdasarkan stabilitas alternatif ketika nilai $v>0.5$, atau $v \approx 0.5$, atau $v<0.5$.

\section{Analisis Sensitivitas}

Analisis sensitivitas digunakan untuk menentukan seberapa sensitif hasil pemeringkatan metode MADM terhadap perubahan bobot.

1. Menaikkan semua bobot kriteria sesuai dengan kondisi yang telah ditetapkan.

2. Menerapkan metode yang akan digunakan.

3. Menghitung persentase perubahan ranking dengan kondisi awal.

$$
\text { PPR }=\frac{A-A *}{A *} \times 100 \%
$$

\section{HASIL DAN PEMBAHASAN}

\section{Penetapan Variabel}

Terdapat 7 dari 8 variabel uji yang valid dan reliabel. Semua variabel uji ditentukan nilai kepentingan terhadap masing-masing golongan yang disebut nilai prioritas. Variabel uji yang digunakan adalah sebagai berikut :

1. Penghasilan orang tua $\left(K_{1}\right)$

TABEL 1. Nilai Prioritas Penghasilan Orang Tua

\begin{tabular}{cc}
\hline Penghasilan Orang Tua & Nilai Prioritas Kriteria \\
\hline$<1.000 .000$ & 6 \\
\hline $1.000 .000-2.000 .000$ & 5 \\
\hline $2.100 .000-3.000 .000$ & 4 \\
\hline $3.100 .000-4.000 .000$ & 3 \\
\hline $4.100 .000-5.000 .000$ & 2 \\
\hline$>5.000 .000$ & 1 \\
\hline
\end{tabular}

2. Jumlah tanggungan kepala keluarga $\left(K_{2}\right)$

TABEL 2. Nilai Prioritas Jumlah Tanggungan Kepala Keluarga

\begin{tabular}{cc}
\hline Jumlah Tanggungan & Nilai Prioritas Kriteria \\
\hline$\leq 2$ & 1 \\
\hline 3 & 2 \\
\hline 4 & 3 \\
\hline 5 & 4 \\
\hline$>5$ & 5
\end{tabular}

3. Kondisi pernikahan orang tua $\left(K_{3}\right)$

TABEL 3. Nilai Prioritas Kondisi Orang Tua

Kondisi orang tua Nilai prioritas kriteria




\begin{tabular}{cc}
\hline Kondisi orang tua & Nilai prioritas kriteria \\
\hline Menikah & 1 \\
\hline Bercerai & 2 \\
\hline Piatu & 2 \\
\hline Yatim & 3 \\
\hline Yatim-Piatu & 4 \\
\hline
\end{tabular}

4. Jumlah semester $\left(K_{4}\right)$

TABEL 4. Nilai Prioritas Jumlah Semester Angkatan Nilai prioritas kriteria

\begin{tabular}{ll}
\hline 2016 & 1 \\
\hline 2017 & 2 \\
\hline 2018 & 3 \\
\hline 2019 & 4 \\
\hline 2020 & 5 \\
\hline
\end{tabular}

5. Nilai IPK $\left(K_{5}\right)$

TABEL 5. Nilai Prioritas Nilai IPK

\begin{tabular}{cc}
\hline Nilai IPK & Nilai prioritas kriteria \\
& \\
\hline IPK $\leq 2.75$ & 1 \\
\hline $2.76 \leq$ IPK $\leq 3.00$ & 2 \\
\hline $3.01 \leq \mathrm{IPK} \leq 3.25$ & 3 \\
\hline $3.26 \leq \mathrm{IPK} \leq 3.50$ & 4 \\
\hline IPK $>3.50$ & 5 \\
\hline
\end{tabular}

6. Jumlah prestasi $\left(K_{6}\right)$

TABEL 6. Nilai Prioritas Jumlah Prestasi

\begin{tabular}{cc}
\hline Jumlah prestasi & Nilai prioritas kriteria \\
\hline 0 & 1 \\
\hline 1 & 2 \\
\hline 2 & 3 \\
\hline 3 & 4 \\
\hline$>3$ & 5 \\
\hline
\end{tabular}

7. Tingkat prestasi $\left(K_{7}\right)$

TABEL 7. Nilai Prioritas Tingkat Prestasi

\begin{tabular}{cc}
\hline Tingkat prestasi & Nilai prioritas kriteria \\
\hline Tidak berprestasi & 1 \\
\hline Prodi & 2 \\
\hline Fakultas & 2 \\
\hline Universitas & 3 \\
\hline Nasional & 4 \\
\hline Internasional & 5 \\
\hline
\end{tabular}

\section{Data Penelitian}

Data yang digunakan dalam penelitian ini merupakan data primer yang didapat dari 131 responden. 
Para responden berasal dari mahasiswa FMIPA UNJ calon penerima KJMU. Berikut adalah data dalam penelitian ini :

\begin{tabular}{|c|c|c|c|c|c|c|c|}
\hline \multirow{2}{*}{ Alternatif } & \multicolumn{7}{|c|}{ Kriteria } \\
\cline { 2 - 8 } & $\mathrm{K}_{1}$ & $\mathrm{~K}_{2}$ & $\mathrm{~K}_{3}$ & $\mathrm{~K}_{4}$ & $\mathrm{~K}_{5}$ & $\mathrm{~K}_{6}$ & $\mathrm{~K}_{7}$ \\
\hline $\mathrm{M}_{1}$ & $4.1 \mathrm{jt}-5.0 \mathrm{jt}$ & 4 & Menikah & 2017 & 3.34 & 0 & - \\
\hline $\mathrm{M}_{2}$ & $2.1 \mathrm{jt}-3.0 \mathrm{jt}$ & 3 & Menikah & 2018 & 3.56 & 2 & Nasional \\
\hline $\mathrm{M}_{3}$ & $2.1 \mathrm{jt}-3.0 \mathrm{jt}$ & 5 & Menikah & 2019 & 3.54 & 0 & - \\
\hline $\mathrm{M}_{4}$ & $3.1 \mathrm{jt}-4.0 \mathrm{jt}$ & 4 & Menikah & 2018 & 3.53 & 0 & - \\
\hline $\mathrm{M}_{5}$ & $1.0 \mathrm{jt}-2.0 \mathrm{jt}$ & 5 & Menikah & 2020 & 3.95 & 0 & - \\
\hline$\vdots$ & $\vdots$ & $\vdots$ & $\vdots$ & $\vdots$ & $\vdots$ & $\vdots$ & $\vdots$ \\
\hline $\mathrm{M}_{131}$ & $2.1 \mathrm{jt}-3.0 \mathrm{jt}$ & 3 & Menikah & 2018 & 3.56 & 0 & - \\
\hline
\end{tabular}

GAMBAR 1. Data Mahasiswa Calon Penerima Beasiswa KJMU

Selanjutnya masing-masing kriteria akan dibentuk dalam bentuk diagram untuk melihat penyebarannya.

\section{Penentuan Bobot}

Terdapat 7 kriteria yang digunakan untuk menentukan penerima terbaik Kartu Jakarta Mahasiswa Unggul (KJMU). Nilai bobot berada di rentang 0 sampai 1. Nilai prioritas tertinggi ditetapkan untuk kriteria ke-1, dengan nilai 9 dan terendah ditetapkan untuk kriteria ke-7, dengan nilai 2. Selain itu, tidak terdapat nilai prioritas 1 dan 5 , nilai 1 dianggap nilai terkecil dan nilai 5 merupakan nilai tengah dari rentang 1-9. Semua nilai prioritas untuk masing-masing kriteria adalah terurut. Nilai bobot untuk masing-masing kriteria dapat dilihat dalam Tabel 8.

Tabel 8. Nilai Bobot masing-masing Kriteria

\begin{tabular}{ccc}
\hline \multicolumn{3}{c}{ Tabel 8. Nilai Bobot masing-masing Kriteria } \\
\hline$K_{1}$ & Kriteria & Bobot \\
\hline$K_{2}$ & Penghasilan orang tua & 0.231 \\
\hline$K_{3}$ & Kondisi pernikahan orang tua & 0.103 \\
\hline$K_{4}$ & Jumlah semester & 0.205 \\
\hline$K_{5}$ & Nilai IPK & 0.179 \\
\hline$K_{6}$ & Jumlah prestasi & 0.154 \\
\hline$K_{7}$ & Tingkat prestasi & 0.051 \\
\hline \multicolumn{3}{c}{ Jumlah } \\
\hline
\end{tabular}

\section{Menyusun Matriks Kriteria-Alternatif}

Matriks kriteria-alternatif berisi nilai prioritas yang bersesuaian berdasarkan kriteria-kriteria yang valid dan alternatif (calon penerima beasiswa) yang tersedia. Persamaan (11) menunjukkan matriks kriteria-altenatif. 


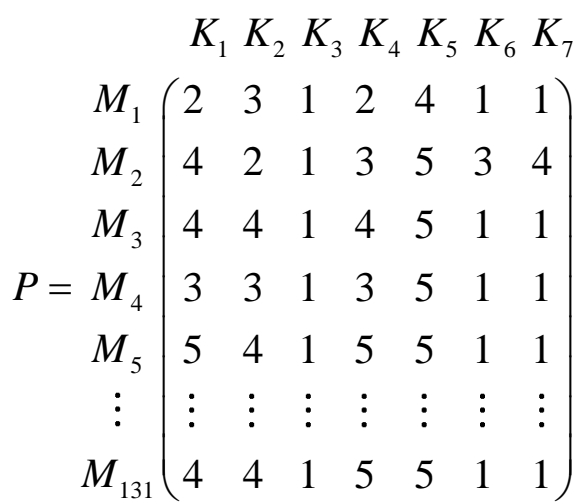

Matriks pada persamaan (11) berukuran $131 \times 7$ yang bermakna terdapat 131 Mahasiswa calon penerima beasiswa (disebut juga alternatif) dengan 7 kriteria yang akan digunakan. $P_{M_{1} K_{1}}=2$ adalah nilai bobot Mahasiswa ke-1 dengan penghasilan orang tua (kriteria 1) sebesar Rp. 4.100.000 5.000.000. Kemudian, $P_{M_{1} K_{\mathrm{m}}}=3$ merupakan nilai bobot Mahasiswa ke-1 dengan jumlah tanggungan kepala keluarga (kriteria 2) sebanyak 4 orang. Seterusnya menggunakan cara yang sama untuk data lainnya.

\section{Penerapan Metode WPM}

Metode WPM dapat diterapkan sesuai langkah-langkah pada bab sebelumnya. Perhitungan metode WPM menggunakan persamaan (2) dan (3), $S_{s}$ dan $v_{s}$ dihitungan untuk masing-masing altenatif $s=1,2, \cdots, 131$. Tabel (8) memberikan nilai untuk $S$ dan $V$ masing-masing alternatif sedangkan Tabel (9) memberikan peringkat yang sesuai.

TABEL 9. Nilai $S$ dan $V$ Metode WPM

\begin{tabular}{ccc}
\hline Alternatif & $S$ & $V$ \\
\hline $\mathrm{M}_{1}$ & 0.9768075 & 0.0087169 \\
\hline $\mathrm{M}_{2}$ & 0.8067573 & 0.0071994 \\
\hline $\mathrm{M}_{3}$ & 0.9662528 & 0.0086227 \\
\hline $\mathrm{M}_{4}$ & 0.9244202 & 0.0082494 \\
\hline $\mathrm{M}_{5}$ & 0.9552587 & 0.0085246 \\
\hline$\vdots$ & $\vdots$ & $\vdots$ \\
\hline $\mathrm{M}_{131}$ & 0.7960056 & 0.0071035 \\
\hline
\end{tabular}

TABEL 10. Peringkat Calon Penerima

\begin{tabular}{cc}
\hline Peringkat & Calon Penerima \\
\hline 1 & $\mathrm{M}_{9}$ \\
\hline 2 & $\mathrm{M}_{93}$ \\
\hline 3 & $\mathrm{M}_{64}$ \\
\hline 4 & $\mathrm{M}_{17}$ \\
\hline 5 & $\mathrm{M}_{75}$ \\
\hline$\vdots$ & $\vdots$ \\
\hline 131 & $\mathrm{M}_{32}$ \\
\hline
\end{tabular}

Tabel (10) menunjukkan hasil perankingan Mahasiswa, terlihat 5 Mahasiswa dengan peringkat tertinggi yakni Mahasiswa ke-9, 93, 64, 17 dan 75 dengan nilai alternatif masing-masing 0.0119, $0.0114,0.0112,0.0111$, dan 0.010 . Pihak pengelola KJMU dapat langsung mengambil $n$ (banyak data) data teratas sesuai kuota yang telah ditetapkan. 


\section{Penerapan Metode VIKOR}

Pertama menentukan nilai $P_{t}^{*}$ dan $P_{t}^{-}$untuk masing-masing kriteria. Setelah itu menggunakan persamaan (4) untuk melakukan normalisasi matriks kriteria-alternatif. Selanjutnya menghitung nilai pada persamaan (6), (7), dan (8) (dengan nilai $v=0.5$ pada $Q_{s}$ ) untuk $s=1,2, \cdots, 131$. Tabel (11) memberikan nilai untuk $S, R$, dan $Q$ masing-masing alternatif sedangkan Tabel (12) memberikan peringkat yang sesuai.

TABEL 11. Nilai $S, R$, dan $Q$ Metode VIKOR

\begin{tabular}{cccc}
\hline Alternatif & $S$ & $R$ & $Q$ \\
\hline $\mathrm{M}_{1}$ & 0.736 & 0.390 & 0.767 \\
\hline $\mathrm{M}_{2}$ & 0.460 & 0.195 & 0.341 \\
\hline $\mathrm{M}_{3}$ & 0.413 & 0.195 & 0.308 \\
\hline $\mathrm{M}_{4}$ & 0.574 & 0.292 & 0.538 \\
\hline $\mathrm{M}_{5}$ & 0.285 & 0.097 & 0.103 \\
\hline$\vdots$ & $\vdots$ & $\vdots$ & $\vdots$ \\
\hline $\mathrm{M}_{131}$ & 0.511 & 0.195 & 0.377 \\
\hline
\end{tabular}

TABEL 12. Peringkat Calon Penerima

\begin{tabular}{cc}
\hline Peringkat & Calon Penerima \\
\hline 1 & $\mathrm{M}_{18}$ \\
\hline 2 & $\mathrm{M}_{98}$ \\
\hline 3 & $\mathrm{M}_{36}$ \\
\hline 4 & $\mathrm{M}_{15}$ \\
\hline 5 & $\mathrm{M}_{9}$ \\
\hline$\vdots$ & $\vdots$ \\
\hline 131 & $\mathrm{M}_{80}$ \\
\hline
\end{tabular}

Tabel (12) menunjukkan hasil perankingan mahasiswa secara keseluruhan. Pada tabel tersebut terlihat 5 Mahasiswa dengan peringkat tertinggi yakni Mahsiswa ke-18, 98, 15, 36 dan 9 dengan nilai alternatif masing-masing $0.917,0.858,0.751,0.748$, dan 0.728 . Pihak pengelola KJMU dapat langsung mengambil $n$ (banyak data) data teratas sesuai kuota yang telah ditetapkan.

\section{Analisis Sensitivitas}

Pada tahapan ini, dilakukan penerapan metode WPM dan VIKOR tetapi dengan bobot yang telah dinaikkan. Besarnya kenaikkan bobot disesuaikan dengan faktor dari 1. Pada penelitian ini dilakukan kenaikan bobot dengan 3 faktor terbesar 1 yakni, 0.5, 0.25, dan 0.01. Berikut adalah hasil uji sensitivitas berdasarkan kenaikan 3 bobot tersebut.

$$
\text { Hasil Uji Sensitivitas }
$$

- Metode WP $=$ Metode VIKOR

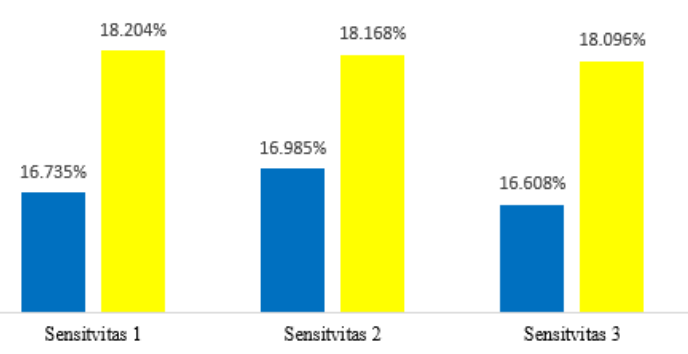

GAMBAR 1. Persentase Perubahan Ranking Hasil Uji Sensitivitas

Uji sensitivitas terhadap metode WPM dan VIKOR dapat dilihat dalam Gambar (1). Berdasarkan gambar tersebut terlihat bahwa metode VIKOR memberikan nilai persentase perubahan ranking 
terbesar yaitu sebesar 18.204\%, 18.168\%, dan 18.096\% dibandingkan metode WPM dengan persentase sebesar $16.735 \%, 16.985 \%$, dan $16.608 \%$. Hal ini berarti bahwa metode VIKOR lebih sensitif terhadap perubahan situasi. Berdasarkan hasil tersebut dapat disimpulkan bahwa metode VIKOR adalah metode yang lebih baik untuk diterapkan dalam penentuan penerima beasiswa KJMU.

TABEL 13. Perubahan Ranking setelah bobot dinaikkan 1 dimulai dari 0.5

\begin{tabular}{ccccccccc}
\hline \multirow{2}{*}{ Iterasi ke- } & Metode & \multicolumn{6}{c}{ Jumlah Perubahan Ranking Kriteria ke- } \\
\cline { 3 - 9 } & & $\mathbf{1}$ & $\mathbf{2}$ & $\mathbf{3}$ & $\mathbf{4}$ & $\mathbf{5}$ & $\mathbf{6}$ & $\mathbf{7}$ \\
\hline \multirow{2}{*}{1} & WPM & 126 & 121 & 72 & 125 & 129 & 115 & 130 \\
\cline { 2 - 9 } & VIKOR & 129 & 127 & 126 & 122 & 129 & 125 & 128 \\
\hline 2 & WPM & 124 & 121 & 72 & 131 & 129 & 115 & 130 \\
\cline { 2 - 9 } & VIKOR & 130 & 127 & 128 & 129 & 131 & 125 & 128 \\
\hline
\end{tabular}

TABEL 14. Perubahan Ranking setelah bobot dinaikkan 1 dimulai dari 0.25

\begin{tabular}{ccccccccc}
\hline \multirow{2}{*}{$\begin{array}{c}\text { Iterasi } \\
\text { Ke- }\end{array}$} & Metode & \multicolumn{7}{c}{ Jumlah Perubahan Ranking Kriteria ke- } \\
\cline { 2 - 9 } & & $\mathbf{1}$ & $\mathbf{2}$ & $\mathbf{3}$ & $\mathbf{4}$ & $\mathbf{5}$ & $\mathbf{6}$ & $\mathbf{7}$ \\
\hline \multirow{2}{*}{1} & WPM & 123 & 121 & 121 & 125 & 128 & 115 & 129 \\
\cline { 2 - 9 } & VIKOR & 127 & 123 & 126 & 129 & 124 & 127 & 127 \\
\hline \multirow{2}{*}{2} & WPM & 129 & 121 & 73 & 129 & 128 & 114 & 129 \\
\cline { 2 - 9 } & VIKOR & 130 & 124 & 126 & 128 & 130 & 128 & 128 \\
\hline \multirow{2}{*}{3} & WPM & 127 & 120 & 73 & 129 & 128 & 114 & 129 \\
\cline { 2 - 9 } & VIKOR & 130 & 124 & 126 & 126 & 130 & 128 & 128 \\
\hline \multirow{2}{*}{4} & WPM & 127 & 120 & 73 & 131 & 129 & 115 & 129 \\
\cline { 2 - 9 } & VIKOR & 130 & 124 & 126 & 126 & 130 & 128 & 128 \\
\hline
\end{tabular}

TABEL 15. Perubahan Ranking setelah bobot dinaikkan 1 dimulai dari 0.01

\begin{tabular}{|c|c|c|c|c|c|c|c|c|}
\hline \multirow{2}{*}{$\begin{array}{c}\text { Iterasi } \\
\text { ke- }\end{array}$} & \multirow[t]{2}{*}{ Metode } & \multicolumn{7}{|c|}{ Jumlah Perubahan Ranking Kriteria ke- } \\
\hline & & 1 & 2 & 3 & 4 & 5 & 6 & 7 \\
\hline \multirow[t]{2}{*}{1} & WPM & 113 & 116 & 68 & 111 & 121 & 104 & 124 \\
\hline & VIKOR & 123 & 123 & 123 & 127 & 116 & 124 & 117 \\
\hline \multirow[t]{2}{*}{2} & WPM & 122 & 122 & 73 & 125 & 126 & 115 & 129 \\
\hline & VIKOR & 123 & 124 & 126 & 129 & 122 & 127 & 128 \\
\hline \multirow[t]{2}{*}{3} & WPM & 125 & 120 & 73 & 125 & 129 & 115 & 129 \\
\hline & VIKOR & 129 & 119 & 126 & 125 & 130 & 128 & 128 \\
\hline \multirow[t]{2}{*}{4} & WPM & 129 & 120 & 73 & 126 & 128 & 114 & 129 \\
\hline & VIKOR & 130 & 121 & 126 & 128 & 131 & 128 & 128 \\
\hline \multirow[t]{2}{*}{5} & WPM & 129 & 121 & 73 & 128 & 127 & 114 & 129 \\
\hline & VIKOR & 130 & 124 & 126 & 126 & 131 & 128 & 128 \\
\hline \multirow[t]{2}{*}{6} & WPM & 128 & 121 & 73 & 130 & 128 & 114 & 129 \\
\hline & VIKOR & 130 & 124 & 126 & 126 & 131 & 128 & 128 \\
\hline \multirow[t]{2}{*}{7} & WPM & 127 & 120 & 73 & 129 & 128 & 114 & 129 \\
\hline & VIKOR & 130 & 124 & 126 & 126 & 131 & 128 & 128 \\
\hline \multirow[t]{2}{*}{8} & WPM & 126 & 120 & 73 & 130 & 129 & 115 & 129 \\
\hline & VIKOR & 130 & 124 & 126 & 126 & 131 & 128 & 128 \\
\hline \multirow[t]{2}{*}{9} & WPM & 127 & 120 & 73 & 131 & 129 & 115 & 129 \\
\hline & VIKOR & 130 & 124 & 126 & 126 & 131 & 128 & 128 \\
\hline \multirow[t]{2}{*}{10} & WPM & 127 & 120 & 73 & 131 & 129 & 115 & 129 \\
\hline & VIKOR & 130 & 124 & 126 & 126 & 131 & 128 & 128 \\
\hline
\end{tabular}

Perubahan ranking yang terjadi pada masing-masing bobot terkecil terjadi pada kriteria ke-3 (kondisi pernikahan orang tua) untuk metode WPM dan kriteria ke-2 (jumlah tanggungan kepala keluarga). Hal ini dapat dilihat dalam Tabel (13), (14), dan (15) . Kedua hasil tersebut menunjukkan kategori 
jumlah tanggungan kepala keluarga dan kondisi pernikahan orang tua tidak terlalu berpengaruh dalam penentuan beasiswa jika dibandingkan dengan kategori lain.

\section{PENUTUP}

\section{Kesimpulan}

Metode Weighted Product (WPM) dan ViÅie Kriterijumsko Kompromisno Rangiranje (VIKOR) adalah metode yang dapat digunakan untuk menentukan keputusan dengan banyak kriteria. Kedua metode tersebut merupakan metode dalam Multiple Atribute Decision Making (MADM). Pada penerapan metode WPM menghasilkan nilai alternatif tertinggi sebesar 0.0119 yang diperoleh oleh Mahasiswa ke-9. Sedangkan pada metode VIKOR menghasilkan nilai alternatif tertinggi sebesar 0.917 yang diperoleh Mahasiswa ke-18.

Hasil uji sensitivitas yang diterapkan pada kedua metode memiliki hasil rata-rata persentase perubahan ranking sebesar $16.776 \%$ untuk metode WPM dan $18.156 \%$ untuk metode VIKOR. Berdasarkan hasil tersebut metode VIKOR lebih diunggulkan untuk diterapkan dalam penentuan keputusan calon penerima beasiswa KJMU. Hal ini menunjukkan bahwa metode VIKOR lebih sensitif terhadap perubahan-perubahan kecil yang terjadi.

Selain itu, perubahan ranking yang terjadi pada masing-masing bobot terkecil terjadi pada kriteria ke3 (kondisi pernikahan orang tua) untuk metode WPM dan kriteria ke-2 (jumlah tanggungan kepala keluarga). Kedua hasil tersebut menunjukkan kategori jumlah tanggungan kepala keluarga dan kondisi pernikahan orang tua tidak terlalu berpengaruh dalam penentuan beasiswa jika dibandingkan dengan kategori lain.

\section{Saran}

Adapun saran yang dapat diberikan dari penulis, yakni Pemprov DKI Jakarta dapat menggunakan metode yang diterapkan dalam penulisan ini, WPM dan VIKOR, atau metode penentuan keputusan yang lain. Selain itu, penulis lain dapat menggunakan metode lain dalam MADM untuk penulisan berikutnya.

\section{REFERENSI}

Elfianty, Lena., Jusuf Wahyudi. (2020). "Implementasi Weighted Product Method pada Pemilihan Peserta dibangum Polda Bengkulu". Prosiding Seminar Nasional Multidisiplin Ilmu Universitas Asahan ke-4 Tahun 2020. 859â€"869.

https://disdik.jakarta.go.id/. [4 Januari 2021]

https://kbbi.web.id/beasiswa. [7 Desember 2020]

Rainer, Dedi. (2017). "Pengertian Beasiswa, Tujuan, Manfaat, Syarat, Jenis, dan Contohnya". https://id.wikipedia.org/wiki/Beasiswa. [7 Desember 2020]

Rao, R. Venkata. (2007). Decision Making in the Manufacturing Environment Using Graph Theory and Fuzzy Multiple Attribute Decision Making Methods. London

Rao, R. Venkata. (2013). Decision Making in the Manufacturing Environment Using Graph Theory and Fuzzy Multiple Attribute Decision Making Methods Volume 2. London http://linkinghub.elsevier.com/retrieve/pii/B9781856174787500118

Yeh, C. H. (2002). "A Problem-based Selection of Multi-attribute Decision-making Methods". International Transactions in Operational Research. 9(2) : 169â $€$ "181. https://doi.org/10.1111/1475-3995.00348 